\title{
Relaciones de poder y guerra
}

\author{
Alfredo LANGa HERRERO \\ Universidad Alice Salomon de Berlín/ IECAH \\ alfredo.langa@iecah.org
}

Recibido: 22-02-2015

Aceptado: 01-02-2016

\section{Resumen}

Este artículo introduce los conceptos de relaciones de poder analizados por Michel Foucault, haciendo hincapié en el vínculo del ejercicio del poder en las relaciones internacionales. Por ello, se analizan el marco de relaciones que el ejercicio de dicho poder genera, así como las tipologías de relaciones entre Estados, que igualmente genera el poder. El artículo presenta los paradigmas de las relaciones internacionales y su evolución en el tiempo, estableciendo puentes con las consideraciones de Foucault con respecto al poder, la guerra, la represión o las razas. En este sentido, el concepto de guerra de razas se antoja fundamental para identificar dicha noción como la versión más extrema del paradigma realista. Dicha guerra de razas no constituye una categoría que integre necesariamente el concepto biológico, sino que se refiere al proceso de imposición de la identidad del grupo dominante, la cual puede contener aspectos étnicos, socioculturales y políticos. No obstante, ni el realismo ni su visión extrema son los únicos paradigmas existentes, ya que la evolución de los paradigmas alternativos ha conllevado la génesis del reflectivismo como alternativa al realismo.

Palabras clave: poder; guerra; relaciones internacionales; realismo; racismo; Foucault.

\section{Power Relations and War}

\begin{abstract}
This article introduces the concepts of power relations of Michel Foucault, taking into account power and international relations. The framework of relationships between States is analysed, as well as relations themselves, both generated by the exercise of power. This article looks at the different paradigms in international relations and their evolution, linking them with Foucault's point of view on power, war, repression or races. In this sense, the concept of race war is identified as the most extreme version of realist paradigm in international relations. Such war does not include necessary a biological concept, but refers to the process of identity imposition by the main dominant groups. However, neither realism nor its extreme version are the only existing paradigms. Reflectivism has crystallized as the result of the evolution of alternative visions to realism.
\end{abstract}

Key words: power; war; international relations; realism; racism; Foucault.

\section{Referencia normalizada}

Langa Herrero A.(2016): "Relaciones de poder y guerra", Política y Sociedad, 53 (2), pp. 603-620.

Sumario: 1. Poder, represión y guerra. 2. Poder, derecho y relaciones internacionales. 3. El realismo en las relaciones internacionales. 4. Guerra de razas y racismo. 5. Visiones alternativas al realismo en las relaciones internacionales y evolución de los paradigmas. 6. Conclusiones. 7. Bibliografía. 


\section{Poder, represión y guerra}

Michel Foucault (2003) estableció una relación directa entre los conceptos de poder político y de poder económico, que ya fue tenida en cuenta por Max Weber (2008: 43), el cual ofreció la siguiente definición de poder: "Poder significa la probabilidad de imponer la propia voluntad, dentro de una relación social, aun contra toda resistencia y cualquiera que sea el fundamento de esa probabilidad". No obstante, para Foucault (2003) la teoría del poder adolece de cierto "economicismo", en referencia a la concepción marxista del poder y a la denominada funcionalidad económica del poder. De esta manera, el poder trata de salvaguardar las relaciones de producción y de mantener una dominación de clase que las fuerzas productivas hicieron posible, por lo que la economía sienta las bases históricas del poder político y éste último se encuentra, de alguna manera, subordinado al poder económico. Sin embargo, ya que para Foucault (1988 y 2003) dicha subordinación no es tal, sino que existe una interrelación entre ambas materializaciones del poder, para librarse del "economicismo" y realizar un análisis del poder al margen de lo económico, plantea que el poder sólo se ejerce y existe por cuanto a que se materializa el acto del poder:

“(...) el poder no es, en primer término, mantenimiento y prórroga de las relaciones económicas, sino, primariamente, una relación de fuerzas en sí mismo" (Foucault, 2003: 23). Por ello, el poder existe exclusivamente en forma de acto o hecho y existe, además, sólo cuando es ejercido por unos sobre otros (Foucault, 1988).

En este sentido, si el poder es ejercido es esencial responder a la cuestión de en qué consiste dicho ejercicio del poder. Al respecto nos brinda dos respuestas: por un lado el poder es fundamentalmente represión. Por otro lado, el poder es la guerra.

Para la primera respuesta, la esencia del poder es la represión y ésta constituye el mecanismo para ejercer dicho poder. Poder es fundamentalmente aquello que reprime. Por ello, para analizar el poder deberíamos analizar los mecanismos de represión, ya que la esencia del poder es la represión y ésta constituye el mecanismo para ejercer dicho poder. También habría que tener en cuenta que el poder no sólo es represión sino igualmente el ejercicio de ésta. Por tanto, el mecanismo de poder es la represión. ${ }^{1}$

Respecto a la segunda respuesta, Foucault propone invertir la famosa proposición de Clausewitz ${ }^{2}$ y esgrime que la política no es más que la continuación de la guerra por otros medios, lo cual tendría como consecuencia que el poder político prorroga los efectos de la última batalla y los desequilibrios que la guerra conllevase. Además, los acontecimientos posteriores en época de paz respecto a las interacciones de los agentes políticos y los cambios en las relaciones de fuerza no serían sino resultado de la guerra anterior, serían secuelas de la guerra (Foucault, 2003). Más aún, el fin de la política

${ }^{1}$ Teoría que Foucault (2003) denomina hipótesis de Reich por Wilhelm Reich (1989) que estudió la relación entre la represión y el materialismo dialéctico en su obra de base psicoanalítica.

${ }^{2}$ En palabras de Clausewitz (2009: 24): "La guerra no es simplemente un acto político, sino un verdadero instrumento político, una continuación de las relaciones políticas, una gestión de las mismas con otros medios". 
sería esa última batalla que acabaría con lo que denomina el "ejercicio del poder como guerra continua"3 (Foucault, 2003: 25).

Todo ello nos llevaría a tres conclusiones:

- Las relaciones de poder se basarían en la relación de fuerza establecida en un momento determinado por la guerra y el poder político perpetúa la relación de fuerza surgida de dicha guerra. Por ello, la política ratifica y confirma el desequilibrio de fuerzas experimentado en la guerra.

- Un sistema político no sería sino la consecuencia o el resultado de una guerra pretérita. La paz y las instituciones surgidas tras la guerra no serían sino el desarrollo de dicha guerra.

- La inversión del sentencia de Clausewitz significa que sólo de la guerra vendrían las decisiones esenciales y sólo una última batalla acabaría con el ejercicio del poder como guerra continua.

En este sentido, Foucault (2003) plantea dos grandes sistemas de análisis del poder. Por un lado, un sistema que concibe al poder como derecho originario que se cede y es conferido de soberanía y tendría como esencia al contrato ${ }^{4}$. Por otro lado, el otro sistema que plantea tendría como esencia a la represión, por lo que los mecanismos de poder serían, fundamentalmente, mecanismos de represión. Así, se encuentran dos sistemas con dos esquemas: el sistema de contrato/opresión y el sistema de guerra/represión. El esquema contrato/represión se refiere al esquema legal o jurídico donde la oposición se encuentra establecida entre lo legítimo y lo ilegítimo. El esquema guerra/represión o dominación/represión la oposición se da entre lucha y sumisión (Foucault, 2003).

Foucault (1988) propone estudiar las relaciones de poder a través de la oposición al ejercicio del mismo, de manera que para estudiar un fenómeno se acude al estudio de su manifestación inversa. Por tanto, para estudiar las relaciones de poder y las formas de poder, acude a las formas de resistencia, a los tipos de lucha que divide en tres tipos:

- Las luchas contra los mecanismos de dominación de tipo étnico, social o religioso;

- las luchas contra la forma de explotación económica y que alejan al individuo de la producción; así como,

- la lucha contra la superestructura, contra las ataduras del individuo respecto a sí mismo y a sus principios y valores que, asimismo, suponen su subordinación respecto a otros. La resistencia no se hará contra las instituciones, entendidas estas como organizaciones físicas, sino contra instituciones que afianzan valores y cimientan una subjetividad, a la cual el individuo se encuentra consciente o inconscientemente vinculado.

${ }^{3}$ Esta hipótesis sería denominada hipótesis de Nietzsche, ya que para Friedrich Nietzsche (1939) poder significa dominación y la vida es un corolario de la guerra. Igualmente la sociedad sería una consecuencia de la guerra (Foucault, 2003).

${ }^{4}$ Para Foucault (2003) si dicho contrato se sobrepasa en sus términos aparecería la opresión. 
No obstante, también contempla el análisis de las relaciones de poder como fundamental para estudiar las instituciones y no al revés. Ya que según él, las instituciones encuentran su fundamento en dichas relaciones de poder, para cuyo estudio plantea una serie de cuestiones esenciales:

- Analizar el sistema de diferenciaciones, ya sean legales, étnicas, tradicionales, económicas o culturales que toda relación de poder desarrolla.

- Los objetivos de los que ejercen el poder de cara, ya sean estos de índole político, económico o religioso, por ejemplo.

- Los instrumentos y herramientas utilizados en el ejercicio de poder, ya sean estos represivos o no.

- Las manifestaciones institucionales del ejercicio del poder.

- El nivel de racionalización del ejercicio del poder y de las relaciones de poder.

\section{Poder, derecho y relaciones internacionales}

Existe un triángulo esencial: poder, derecho, verdad. Por ello, se hace fundamental estudiar las reglas del derecho que las relaciones de poder articulan para fabricar la verdad. No hay ejercicio de poder sin la generación de discursos de verdad. "El poder nos obliga a producir la verdad dado que la exige y la necesita para funcionar" (Foucault, 2003: 30).

El ordenamiento jurídico y el derecho suponen el catalizador constante de las relaciones de poder y de dominación. El derecho no habría que interpretarlo con respecto a la legitimación que pretende establecer, sino respecto a los aparatos y dispositivos de represión que pone en marcha y articula. Por ello, se hace necesario tomar algunas cuestiones en consideración:

- El análisis de las formas legítimas y legales del poder no habría que llevarlo a cabo en su centro sino en los extremos. "Captar el poder del extremo cada vez menos jurídico de sus ejercicio" (Foucault, 2003: 33).

- Analizar el lado externo del poder y no el interno (quién tiene el poder o cómo lo ejerce). Habría que analizar a los súbditos y a los sujetos, a la periferia del poder y no tanto al centro del mismo.

- No analizar el poder como algo homogéneo y rudo, sino como algo que actúa en cadena y se articula y ejerce en red. El poder se ejerce y se sufre por parte de los individuos que forman la periferia del mismo. "El poder transita en los individuos, no se aplica a ellos" (Foucault, 2003: 34). Por tanto el individuo sería una consecuencia y un resultado del poder y no quien está al frente de su ejercicio.

- Habría que analizar el poder desde los extremos o la periferia, desde los individuos hasta el centro y no al revés. No nos importa tanto conocer los mecanismos de conexión y articulación del poder desde el centro a la periferia, sino desde los extremos al centro, porque en los extremos es donde se ejercen los mecanismos de poder, sus técnicas, estrategias y procedimientos. 
- El ejercicio del poder necesita de la formación, organización y establecimiento de un aparato de conocimiento, por ello es fundamental analizar los mecanismos del saber y no tanto los cuerpos ideológicos.

En definitiva, tal y como el propio Foucault (2003: 38) apuntaba:

“(...) creo que el análisis del poder debe encauzarse hacia la dominación (y no la soberanía), los operadores materiales, las formas de sometimiento, las conexiones y utilizaciones de los sistemas locales de ese sometimiento y, por fin, hacia los dispositivos de saber".

Estudiar el proceso de dominación resultaría fundamental para el análisis de poder. Para ello Foucault (2003) plantea las siguientes cuestiones:

- Analizar el proceso de conformación de las relaciones de dominación concretas.

- Identificar dichas relaciones de sometimiento y dominación como variadas y múltiples e incluso heterogéneas y no verlas como un bloque homogéneo. Esto a pesar de que se pueden identificar grandes aparatos de poder.

- Analizar las técnicas, su heterogeneidad y sus efectos de sometimiento: "La fabricación del sujeto más que la génesis del soberano" (Foucault, 2003:45).

Bajo el orden pacífico establecido, debajo del sistema político y judicial del Estado lo que subyace es una guerra permanente. Por ello, Foucault (2003 y 2006) se cuestiona si en realidad las instituciones militares no son el núcleo del conjunto de instituciones políticas y si en la creación del Estado moderno subyace la esencia misma de la guerra, ya que el Estado circunscribe la formación del ejército y su conformación profesional. La creación del Estado moderno llevará intrínseca, por tanto, su vinculación con la guerra y ésta define la evolución y las relaciones en el Estado y su sociedad, así como las relaciones entre los Estados y sus sociedades.

En este sentido, Foucault (2003 y 2006) considera que la consumación de la guerra no permite la aparición del poder político, sino que éste y sus instituciones, organización social y ordenamiento jurídico nacen de la guerra. La ley nacería, según Foucault (2003 y 2006), de las cenizas y los cadáveres provocados por las batallas, por lo que ley no es sinónimo de pacificación. Para Foucault (2003: 50):

"La guerra es el motor de las instituciones y el orden. La paz hace sordamente la guerra hasta en el más mínimo de sus engranajes".

En la Edad Moderna, para Michel Foucault (2003) hay un autor esencial que emplaza, en un primer momento, a la guerra como analizador de las relaciones de poder y por ende a las relaciones internacionales, y ese autor es Thomas Hobbes. Hobbes (1980) ubica la guerra como base y principio de las relaciones de poder, la sitúa en el transfondo de la legalidad y del orden establecidos por el Estado, por el Leviatán. Esta guerra no era sólo la guerra entre Estados, sino que la denomina "guerra de todos 
contra todos", desplegada en todo momento y en todas las dimensiones. En palabras del propio Hobbes (1980: 104):

"Fuera del estado civil hay siempre guerra de cada uno contra todos. Con todo ello es manifiesto que durante el tiempo en que los hombres viven sin un poder común que los atemorice a todos, se hallan en la condición o estado que se denomina guerra; una guerra tal que es la de todos contra todos".

De ello se deduce que en la tradición hobbesiana la interacción de los Estados se basa en la guerra y ésta es inevitable porque se considera intrínseca a la naturaleza del ser humano. En dicha naturaleza encuentra Hobbes las tres causas principales de conflicto y discordia: la competencia, la desconfianza y la gloria ${ }^{5}$. La competencia induce a los hombres a agredirse en pro de un beneficio; la desconfianza sirve para alcanzar seguridad; y la gloria para conquistar reputación.

Según Foucault (2003), para Hobbes, además la guerra de "todos contra todos" la establece antes de la existencia del Estado, antes de la creación del Leviatán ${ }^{6}$, por lo que existe una guerra primitiva anterior a la creación del Estado y una guerra tras su creación. La guerra es un producto de la igualdad entre los hombres y no de la desigualdad, según la interpretación que Foucault (2003) nos brinda. Esta igualdad significa que, aún siendo conscientes de que los hombres no son iguales entre sí, esa igualdad es mayor que las diferencias que manifiestan. Por ello, la guerra es un producto de la existencia de diferencias insuficientes, ya que si la desigualdad fuese suficientemente grande no existirían guerras, por ejemplo, entre Estados, ya que dicha desigualdad, haría que la guerra se bloqueara ${ }^{7}$. De esta manera, Foucault (2003) concluye que existe una relación

5 "La primera hace uso de la violencia para convertirse en dueña de las personas, mujeres, niños y ganados de otros hombres; la segunda, para defenderlos; la tercera, recurre a la fuerza por motivos insignificantes, como una palabra, una sonrisa, una opinión distinta, como cualquier otro signo de subestimación, ya sea directamente en sus personas o de modo indirecto en su descendencia, en sus amigos, en su nación, en su profesión o en su apellido" (Hobbes, 1980: 102).

6"La naturaleza es el arte con que Dios ha hecho y gobierna el mundo. Este arte va aún más lejos, imitando esta obra racional, que es la más excelsa de la Naturaleza: el hombre. En efecto: gracias al arte se crea ese gran Leviatán que llamamos república o Estado (en latín civitas) que no es sino un hombre artificial, aunque de mayor estatura y robustez que el natural para cuya protección y defensa fue instituido y en el cual la soberanía es un alma artificial que da vida y movimiento al cuerpo entero (...)" (Hobbes, 1980: 3).

${ }^{7}$ Para Hobbes (1980:10): "La guerra no consiste solamente en batallar, en el acto de luchar, sino que se da durante el lapso de tiempo en que la voluntad de luchar se manifiesta de modo suficiente. Por ello la noción del tiempo debe ser tenida en cuenta respecto a la naturaleza de la guerra, como respecto a la naturaleza del clima. En efecto, así como la naturaleza del mal tiempo no radica en uno o dos chubascos, sino en la propensión a llover durante varios días, así la naturaleza de la guerra consiste no ya en la lucha actual, sino en la disposición manifiesta a ella durante todo el tiempo en que no hay seguridad de lo contrario. Todo el tiempo restante es de paz". 
vital entre Estado y guerra, ya que según la obra de Hobbes, lo que crea el Estado y lo conforma es la situación de "no guerra".

\section{El realismo en las relaciones internacionales}

En este sentido, es importante tener en cuenta que las ideas de Hobbes crearon las bases de la denominada tradición hobbesiana o realista de las relaciones internacionales, que supone un enfoque pesimista, donde las mismas presumen un conflicto permanente entre los Estados, y la política internacional no es más que política de fuerza. Por ello, la interacción entre los Estados nación se fundamenta en la guerra y ésta se hace inevitable porque se confiere inherente al hombre y a su naturaleza egoísta y de lobo para el hombre ${ }^{8}$ (García Picazo, 2006). La moral y la ley no existen en las relaciones entre Estados e impera, en el escenario internacional, una lucha de todos contra todos. Tan sólo existiría un principio de prudencia que cada Estado ha de tener antes de iniciar una guerra (Barbé, 2007). De esta manera, los periodos de paz supondrían sólo espacios de tiempo entre una y otra batalla, y los acuerdos de paz y altos el fuego se cumplirían tan sólo mientras sirvan a los intereses del Estado. Por ello, igualmente Foucault (2003) participa de esta visión pesimista de las relaciones entre naciones.

La tradición realista o paradigma realista cristalizó como fruto de una práctica de las relaciones internacionales que tiene sus orígenes en el mundo antiguo grecolatino de Tucídides, la India de Kautilya o la China de Mencio, y encontró su continuación en el Renacimiento con Maquiavelo y sobre todo con Thomas Hobbes. Su versión más moderna y actual se conformó a partir de los años treinta del siglo XX, y tras la Segunda Guerra Mundial y la llegada de la Guerra Fría, su consolidación ha supuesto el fracaso del denominado "espíritu de Ginebra" y el advenimiento del "espíritu de Yalta $^{10}$ ", con el dominio de la realpolitik y el equilibrio de poderes entre potencias hegemónicas (Barbé, 2007).

El actor fundamental de esta visión del mundo es el Estado nación, surgido de la Paz de Westfalia, y el poder se torna factor decisivo de las relaciones internacionales, por lo que relaciones internacionales se caracterizan por la legitimidad que los Estados otorgan al uso de la fuerza armada, así como en la separación de los ámbitos políticos

${ }^{8}$ Fue Hobbes quien dijo homo homini lupus -el hombre es un lobo para el hombre-, abreviando la frase de Tito Marcio Plauto de su obra Asinaria: Lupus est homo homini, non homo, quom qualis sit non novit -lobo es el hombre para el hombre, y no hombre, cuando desconoce quién es el otro- (García Picazo, 2006).

${ }^{9}$ Hace referencia a una atmósfera de diálogo y arbitraje de las relaciones internacionales. Según François Nordmann, embajador de Suiza ante las organizaciones internacionales en Ginebra: "El espíritu de Ginebra se alimenta a la vez del cosmopolitismo que se desarrolló al cabo de siglos en una ciudad obligada por su aislamiento geográfico a abrirse al mundo y de la dimensión internacional que le ha dado la Sociedad de las Naciones. No es una mística sino el resultado de una actividad diplomática multilateral" (Arenal, 2007: 30).

${ }^{10}$ Se refiere al reparto de Europa entre Estados Unidos y la Unión Soviética, y el establecimiento de sus respectivas áreas de influencia. 
interno e internacional de la política interna y de la política internacional, en la cual la moral imperante cristaliza en valores como la seguridad y el poder por encima de otras consideraciones (Arenal, 2007). Las relaciones entre Estados serían de índole competitiva tendente al conflicto y dependientes de las relaciones de poder, el cual se configura como un fin y como un medio de ejercer la política internacional, quedando lo político sometido a lo militar y a lo estratégico (García Picazo, 2006).

Figura 1: Bases del realismo económico y los conflictos

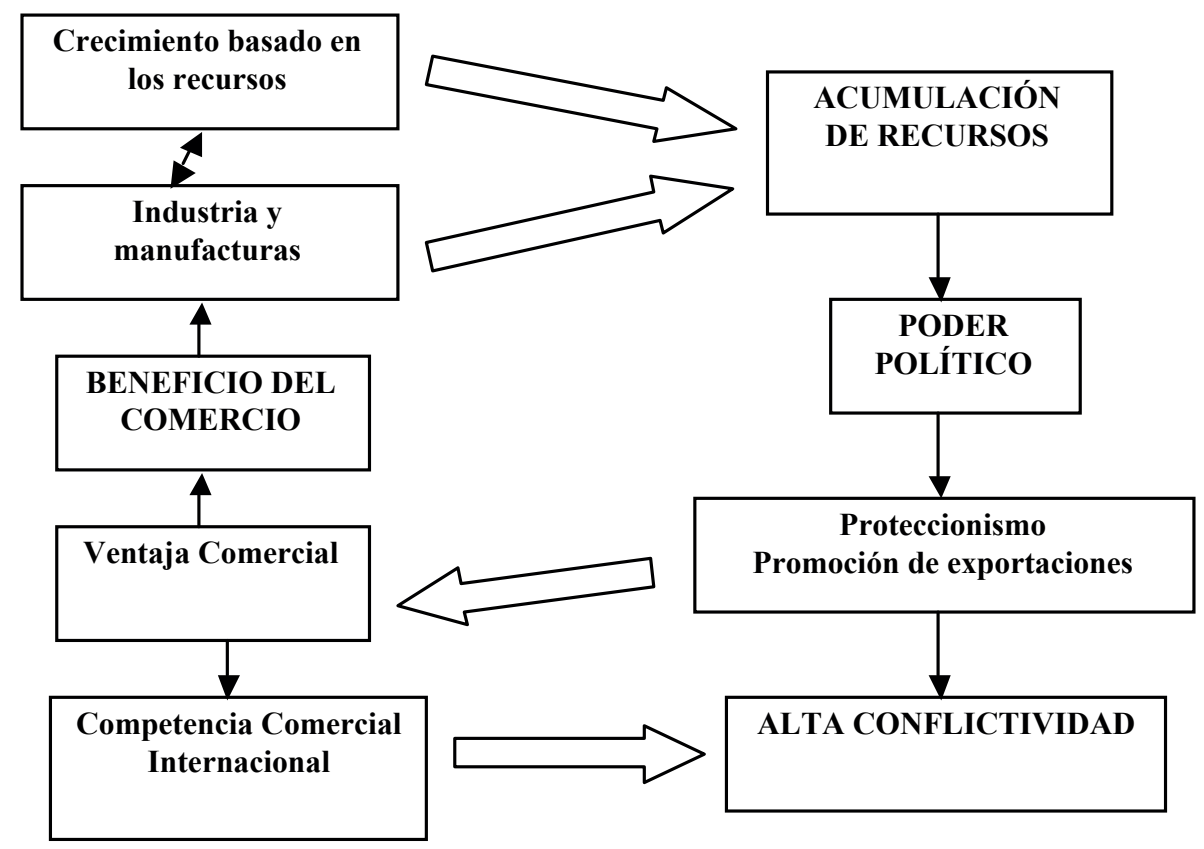

Fuente: Montt (1997:53)

Hans J. Morgenthau, Edward H. Carr, Raymond Aron y Martin Wight, entre otros, constituyen las principales figuras contemporáneas del paradigma realista ${ }^{11}$. Según Morgenthau, la esencia de la teoría realista residiría en la lucha constante y perpetua por el poder, existiendo tres formas de política internacional: la política de status

${ }^{11}$ Del Arenal (2007) señala que el realismo gozó de su principal expresión práctica mediante la puesta en marcha de la visión teórica y diplomática de Henry Kissinger, quien fuera Secretario de Estado de EEUU con Richard Nixon como presidente. Kissinger diferencia entre dos modelos de análisis de política internacional: el que denomina sistema estable y el sistema revolucionario. 
$q u o$, la política imperialista y la política del prestigio, dependiendo de que el Estado pretenda mantener el poder, extenderlo, u ostentarlo, respectivamente. De esta forma, el equilibrio en las relaciones internacionales se lograría mediante constantes ajustes, con el desafío y la amenaza como elementos de las relaciones de poder (Arenal, 2007; García Picazo, 2006).

No obstante, en el concepto de guerra de razas desarrollado por Foucault (2003) se encuentra una de las versiones más radicales de dicho realismo y del nacionalismo implícito en el mismo. La noción de raza llevaría implícita un componente de guerra permanente hacia el interior y el exterior que define las relaciones internacionales tal y como presenta el siguiente apartado.

\section{Guerra de razas y racismo}

Para desarrollar el concepto de guerra de razas, Foucault (2003) se sirve de dos fuentes fundamentales: por un lado de las demandas populares en la Inglaterra revolucionaria y prerrevolucionaria del siglo XVII ${ }^{12}$, y por otro, del discurso de la aristocracia francesa contra el rey Luis XIV al final de su mandato. De ambos surgiría la concepción de una sociedad basada en dos razas y la consecuente guerra entre ambas. No obstante, dicha lucha no considera una dicotomía entre dos sujetos homogéneos, sino que del discurso subyace de la lucha entre una raza principal y otra subalterna, o la escisión de una única raza en dos razas heterogéneas (Foucault, 2003).

Dicha idea de escisión o desdoblamiento, que surgió en el siglo XVII, encontrará continuidad en el discurso revolucionario de la Francia de 1789 y en la lucha de los movimientos nacionalistas contra la metrópolis rusa o la austrohúngara, en el siglo XIX. Asimismo, la traslación de la guerra de razas al discurso social derivaría en la noción de lucha de clases $^{13}$. Sin embargo, el poder central adaptará el discurso a la realidad del Estado moderno, lo que desembocará en la génesis de un racismo de Estado a principios del siglo XX. De esta forma, la raza principal o superraza que detenta y ejerce el poder del Estado ha de defenderse de la otra raza que por motivos sociales, políticos o biológicos supone una amenaza. Por ello, la guerra de razas no se limitó a ser un discurso de los oprimidos o explotados, sino que su base reivindicativa se transformó y se adaptó a los discursos racistas de la colonización (Foucault, 2003).

Por ende, el término raza no alude a un sentido sólo biológico sino que hace referencia a dos grupos que no tienen el mismo origen local. Igualmente pueden no hablar la misma lengua ni profesar la misma religión y si han estado o están unidos políticamente no es sino por el vínculo de la guerra, tras pagar el precio de las batallas y la conflagración. En palabras del propio Foucault (2003: 71):

\footnotetext{
${ }^{12}$ Foucault (2003) se refiere a las reivindicaciones de puritanos y el grupo de los "niveladores" -Levellers- respecto a los derechos políticos. También hizo referencia a las diferencias ente francos y galos y como éstas supusieron un primer ejemplo de guerra de razas.

${ }^{13}$ Al respecto Foucault (2003) cita la carta de Karl Marx a J. Weydemeyer en la que el primero menciona que referencia esencial para desarrollar su concepto de lucha de clases fueron historiadores franceses, como Agustin Thierry o François Guizot.
} 
"Se dirá, por último, que hay dos razas cuando hay dos grupos que, pese a su cohabitación, no están mezclados a causa de diferencias, disimetrías, barreras debidas a los privilegios, las costumbres y los derechos, la distribución de las fortunas y el modo de ejercicio del poder".

La sociedad fraccionada en dos razas, que en un primer momento sentó su dicotomía sobre la base histórica, a su vez fundamentada en la guerra, más tarde cimentaría la lucha de razas en una concepción biológica de la misma. De esta manera, la sociedad binaria resultaría del enfrentamiento entre un cuerpo social homogéneo y un conjunto de individuos heterogéneos de los cuáles hay que defenderse. Para ello, el Estado pasa de ser el instrumento de una raza contra otra a ser el defensor de la sociedad o la raza homogénea. Según Foucault (2003), en el momento en que la cuestión de la integridad de la raza suplanta a la guerra de razas surge el concepto de racismo, Y dicho racismo surge de la evolución de la guerra de razas, por lo que no supone un discurso paralelo, sino parte del discurso de la guerra de razas. Se configura, de hecho, como su dorso o su negativo. De esta manera, el discurso revolucionario de la guerra de razas se metamorfoseó en el racismo. Dicho racismo, no obstante, evolucionó en el siglo XX en un tipo de racismo de corte biológico y centralizado, que Foucault (1988 y 2003) refleja en dos formas de poder que considera "patológicas" o enfermizas: el nazismo y el comunismo soviético.

El nazismo retomaría los ideales de finales del siglo XIX respecto a la necesidad de defensa de la pureza de una raza, siendo el Estado la principal herramienta para llevar a cabo dicho empeño. El Estado sería, por tanto, el principal garante de la limpieza biológica de la raza. Curiosamente dicho discurso racista de tipo biológico sería el producto de la transformación del discurso de la lucha de razas, por lo que aún toma elementos de dichas luchas revolucionarias populares y por ello se hace uso de la raza alemana como grupo biológico dominado y humillado por el Tratado de Versalles y por las potencias aliadas de la I Guerra Mundial, así como por judíos o eslavos (Foucault, 1988 y 2003).

El auge de este biopoder extremo se combinó con un sistema basado en el nacionalismo económico, que fue puesto en práctica de manera evidente en la Italia fascista y en la Alemania nacionalsocialista ${ }^{14}$. Estos regímenes totalitarios compartían elementos políticos derivados del control represivo del Estado, así como de una forma de capitalismo dirigido hacia los intereses nacionales, los cuales contenían el discurso de la lucha de razas aplicados al ámbito económico (Foucault, 1988 y 2003; Sternhell et al., 1994). La economía fascista intentaría modificar los principios de las relaciones entre el Estado y los individuos sin quebrantar el modelo de producción capitalista, criticado por muchos autores fascistas. La visión económica fascista no desterraría la noción de economía de mercado, ni de propiedad privada, así como tampoco la existencia del beneficio, sino que estableció un marco de control de la economía

${ }^{14}$ En general, se hablará de régimen fascista para hacer referencia a todos los regímenes totalitarios. 
capitalista que contribuyera a los intereses estatales ${ }^{15}$ (Hernández Sandoica, 1992). Por ello, el fascismo ha sido calificado como antimaterialista, porque rechaza tanto al liberalismo como al socialismo, a los que califica de "materialistas", aunque toma de ambos elementos esenciales (Sternhell et al., 1994).

El racismo de los soviets, por su parte, deviene de la transformación de la lucha de razas -de la lucha de clases, concretamente-, en una forma de racismo que combate al individuo no revolucionario. El denominado enemigo de clase se convierte en un desviado o un perturbado en el seno de la sociedad soviética cuando no hay ya necesidad de combatirle. En ese momento se lucha de una forma casi biológica contra la degeneración de la raza revolucionaria y le corresponde al Estado defender la pureza de dicha raza (Foucault, 1988 y 2003).

Además, desde el punto de vista económico, con la llegada al poder de Stalin y su Nueva Política Económica, se constituyeron los denominados planes quinquenales que favorecían el desarrollo de la industria pesada y del armamento en detrimento de la agricultura y los bienes de consumo. La industria militar y la consecuente militarización de la economía resultaron fundamentales para el despegue de la Unión Soviética a pesar de las críticas al militarismo que Marx, Engels o Rosa Luxemburgo manifestaran. La Unión Soviética se convirtió en una potencia política y económica altamente militarizada, lo cual tendría consecuencias en el desarrollo de los regímenes socialistas (Coulomb, 2004).

De esta manera, según Foucault (2003), el racismo se convierte en el siglo XIX y XX en un mecanismo esencial del poder del Estado moderno: "(...) en el sentido en que hace que prácticamente no haya funcionamiento moderno del Estado que, en cierto momento, en cierto límite y ciertas condiciones, no pasé por él" (Foucault, 2003:218). Esto no significa que el racismo sea un fenómeno nuevo, sino que la asimilación del mismo como parte del Estado moderno es lo que resulta innovador. Sobre todo porque para Foucault (2003) el racismo asume dos funciones fundamentales:

- Por un lado, articula la decisión sobre la vida de los individuos de la sociedad. El poder de base biológica inscribe al racismo como mecanismo del Estado y mediante el mismo se categoriza a las razas y a los grupos humanos y se las califica de manera positiva o superior y negativa o inferior sana (Foucault, 2003).

- Por otro lado, el racismo transforma la relación en la guerra de manera que la aniquilación del enemigo no es ya necesaria para la supervivencia dentro de una lógica de guerra, sino que la erradicación de la otra raza lleva un componente biológico de limpieza racial. La otra raza, la negativa, la inferior ha de ser aniquilada como parte de un proceso de purificación de la raza principal, positiva

${ }^{15}$ Quizás esto explique que el nacionalsocialismo en Alemania, dentro del desarrollo de la economía de guerra y de la guerra de razas, con el componente de biopoder radicalizado al extremo, pusiera en marcha actividades de gran ineficiencia económica. Al respecto, Hanna Arendt (1951) señalaría que el establecimiento de los campos de concentración y de exterminio fue totalmente inútil y absurdo económicamente. 
o superior. En definitiva, el fin de la otra raza hace la vida mejor, más pura y más sana (Foucault, 2003).

De esta manera, dentro de un Estado gobernado por lo que Foucault (2003) denomina biopoder, ejercido como la supremacía biológica de una raza, el racismo es el fenómeno que hace posible el asesinato y la aniquilación del otro. El racismo se confiere como el instrumento clave para el ejercicio de la soberanía del Estado sobre los individuos. Y esto, no sólo respecto a la muerte física, sino en lo referente a otros tipos de aniquilación, como la política, la social o mediante la exclusión o el repudio.

Para llegar a dicho extremo, Foucault (2003) esgrime que dicho racismo dentro de un Estado moderno regido por el biopoder sólo pudo cristalizar a través del evolucionismo social que trató de justificar, mediante argumentos pseudocientíficos, la superioridad de unas razas sobre otras o de la "civilización" sobre los "salvajes". Y todo ello, materializado en el proceso de colonización a lo largo del siglo XIX en cuyo seno el racismo fue fundamental para entender el asesinato y la represión, y en algunos casos, el genocidio. Por consiguiente, los Estados modernos en su proceso colonizador materializaron un racismo de guerra que era utilizado por el biopoder con una función de exterminio del otro para fortalecimiento de la raza y la sociedad proclamada como superior y a la que hay que proteger (Foucault, 2003).

\section{Visiones alternativas al realismo en las relaciones internacionales y evolución de los paradigmas}

Aparte del paradigma realista de las relaciones internacionales con su versión extrema expuesta anteriormente, otras dos teorías o tradiciones de pensamiento han sido definidas, de cara a dar respuesta a los modos de articulación de las relaciones de poder en el ámbito internacional. Estos dos paradigmas alternativos al realista son los siguientes: el denominado paradigma de la sociedad mundial o transnacionalista, y el paradigma de la dependencia o estructuralista ${ }^{16}$.

Respecto al paradigma de la sociedad mundial o transnacionalista, éste comienza a germinar en los años 60, tras los primeros atisbos de distensión entre las potencias hegemónicas de la época, y se desarrolló, sobre todo en los años 70, aunque con una tradición anterior que culminó en Kant. En este sentido, Kant acuñó el término de "paz perpetua" que contrasta con las tesis realistas. En su obra "La Paz Perpetua" hace aseveraciones tales como que ningún tratado de paz debe ser firmado si hay una reserva tácita para futuras guerras, por lo que trata de suprimir la guerra como instrumento de resolución de conflictos entre naciones, abogando, de este modo por el diálogo internacional.

${ }^{16}$ MartinWight planteó introducir un cuarto paradigma basado en la visión internacional de Gandhi (Barbé, 2007). 
Tabla 1: Características de los paradigmas en las relaciones internacionales

\begin{tabular}{|l|l|l|l|}
\hline & Realismo & Transnacionalismo & Estructuralismo \\
\hline $\begin{array}{l}\text { Contexto } \\
\text { histórico }\end{array}$ & Guerra Fría & Distensión & Postdescolonización \\
\hline $\begin{array}{l}\text { Unidad } \\
\text { de análisis }\end{array}$ & $\begin{array}{l}\text { Estado como } \\
\text { unidad racional }\end{array}$ & $\begin{array}{l}\text { Pluralidad de actores } \\
\text { internacionales } \\
\text { (gubernamentales } \\
\text { y no gubernamentales) }\end{array}$ & $\begin{array}{l}\text { Sistema económico } \\
\text { capitalista mundial }\end{array}$ \\
\hline $\begin{array}{l}\text { Problemática } \\
\text { de estudio }\end{array}$ & $\begin{array}{l}\text { Seguridad nacional } \\
\text { (de base militar) }\end{array}$ & $\begin{array}{l}\text { Problemas de la actividad } \\
\text { desarrollado (cuestiones } \\
\text { medioambientales, } \\
\text { comerciales, etc.) }\end{array}$ & $\begin{array}{l}\text { Relaciones } \\
\text { centro-periferia } \\
\text { y mecanismos } \\
\text { generadores } \\
\text { del subdesarrollo }\end{array}$ \\
\hline $\begin{array}{l}\text { Imagen } \\
\text { del mundo }\end{array}$ & $\begin{array}{l}\text { Mesas de bolas } \\
\text { (conflicto) }\end{array}$ & $\begin{array}{l}\text { Red o telarana } \\
\text { (interdependencia) }\end{array}$ & $\begin{array}{l}\text { Pulpo de varias cabezas } \\
\text { alimentado por los } \\
\text { tentáculos }\end{array}$ \\
\hline
\end{tabular}

Fuente: Esther Barbé (2007: 62-70).

Para esta forma de ver las relaciones internacionales, el paradigma realista no estaba dando respuesta a la nueva realidad internacional sin entender el nuevo escenario. Tal y como señalaría Robert Keohane:

"La política internacional contemporánea debido a que el desarrollo teórico de nuestra disciplina va actualmente por detrás de la cambiante realidad de la práctica diaria de los asuntos internacionales. En consecuencia, algunas de nuestras conceptualizaciones más utilizadas, de nuestras imágenes del mundo, producen menos conocimientos de los que nos proporcionaron en el pasado" (citado por Barbé, 2007:64).

De la misma forma, Ray Maghroori (citado por Arenal, 2007:32) apuntaría el siguiente argumento:

"La inutilidad de la fuerza, aunada a la proliferación de las organizaciones internacionales y el surgimiento de la interdependencia, sugiere a los globalistas que los 
Estados ya no estarán preocupados por las cuestiones de seguridad que dominaron la política internacional a los largo de la década de los 60 ”.

En consecuencia, los promotores de la perspectiva transnacionalista han percibido el paradigma realista como "pasado de moda", por lo que hacen hincapié en la política transnacional y en los aspectos económicos y científico-técnicos de las relaciones internacionales, cuya esencia no está en la lucha de poder y el conflicto, sino en la cooperación. Autores como Joseph Nye, los mencionados Kehoane y Maghroori, o Karl Kaiser critican el viejo paradigma realista por cuanto no tiene en cuenta a los nuevos actores no estatales y a los procesos transnacionales.

Este paradigma transnacionalista defiende la existencia de una sociedad mundial que emana de la interdependencia y la cooperación creciente entre los diversos actores mundiales, que no son sólo estatales, ni que sólo se mueven por factores políticos, sino que también actúan por motivaciones económicas, culturales o tecnológicas (Arenal, 2007). Además, el propio Estado nación, debido a los cambios de los últimos años y a la creciente importancia de los nuevos actores no estatales, ha perdido importancia y su papel se ha atenuado. Por tanto, el sistema internacional no es ya "estatocéntrico" como antaño. Esto ha traído, como principal consecuencia, el desvanecimiento de la división entre el ámbito interno del Estado y el ámbito internacional, que quedan diluidos por la interdependencia y la dificultad de separar dichos ámbitos. Por ello, la visión hobbesiana de la relación entre Estados quedaría en entredicho y una alternativa de comunidad mundial basado en el diálogo y la negociación política se impondría frente a la visión de una guerra permanente entre naciones. Subyace en esta visión transnacionalista un enfoque claramente liberal en lo político y no tan claro en lo económico, aunque las experiencias de integración internacional basadas en aspectos mercantiles, serían muestra de ello.

El paradigma de la dependencia o estructuralista, por su parte, se concibe paralelo al paradigma transnacionalista pero con aproximaciones ideológicas diferentes. Al igual que en el transnacionalismo, se confieren de gran importancia las relaciones económicas internacionales, pero en lugar de una relación de interdependencia, para los estructuralistas existe una relación de dependencia en las relaciones económicas internacionales. La interdependencia significa, para los estructuralistas, dominación, explotación y desigualdad, y para ellos, el sistema internacional y el sistema económico capitalista son las fuentes y orígenes de dicha sumisión, explotación, injusticia, desigualdad y, en definitiva, del subdesarrollo (Arenal, 2007). Por tanto, estamos ante una visión marxista de las relaciones internacionales donde la estructura define la superestructura y donde las relaciones de dominación subyacentes en las relaciones productivas trascienden a las relaciones entre Estados y se reproducen a nivel internacional.

Para los estructuralistas, en el planeta sólo existe un único sistema económico, el capitalismo transnacional. Capitalismo que no aporta cooperación e integración, sino que se constituye en el problema y la causa del subdesarrollo. Por ello, el sistema internacional se basa en el conflicto entre dominadores y dominados, opresores y oprimidos, explotadores y explotados, ganadores y perdedores, entre Norte y Sur, 
entre centro y periferia ${ }^{17}$, y la desigualdad mundial es característica inherente al propio sistema capitalista de acumulación. El desarrollo y el subdesarrollo constituyen las dos caras de la misma moneda y dependen entre sí. Dicho sistema capitalista, además, supone el principal objeto de análisis, y el Estado no es el único actor, aunque de gran importancia, sino que existen otros actores no estatales primordiales, como son las empresas transnacionales o los movimientos de liberación (Arenal, 2007).

Por otro lado, desde la década de los ochenta se han desarrollado multitud de diferentes teorías en el marco de los paradigmas anteriormente descritos. Como punto de partida, Waever presenta el debate entre paradigmas como un debate entre posiciones contrapuestas donde el diálogo no tiene lugar. De este modo, los paradigmas realista, estructuralista y transnacionalista permanecen equidistantes, manteniendo sus características y sus diferencias.

Posteriormente, al final de la Guerra Fría, se da un acercamiento entre el transnacionalismo y el realismo, manteniendo un diálogo intenso y dando lugar al denominado debate neo-neo. Este nuevo debate parte de la transformación de los antiguos paradigmas realista y transnacionalista o liberal, en los paradigmas neorrealista y neoliberal, respectivamente. Por otro lado, las teorías estructuralistas pasan a tener diversas denominaciones que hacen referencia a su crítica de las teorías neorrealista y neoliberal y que resumiremos como postpositivismo o reflectivismo.

Por último, Waever, determina que ya en los años 90, se produce un acercamiento definitivo entre los paradigmas neorrealista y neoliberal, y ésta aproximación daría como resultado la denominada síntesis neo-neo o el denominado racionalismo. Además, las teorías que se englobaban dentro del postpositivismo o reflectivismo mantienen su posición irreconciliable con la nueva síntesis racionalista, aunque para algunos autores entraría en escena la teoría constructivista que sirve de enlace entre las anteriores, ya que mantendría el diálogo tanto con racionalistas como con reflectivistas

Por lo tanto, y según la evolución de Waever que trata la profesora Barbé (2007), se identifican una serie de dinámicas, en el desarrollo de las Relaciones Internacionales, en los últimos años, que caracterizaremos de la siguiente manera: diálogo Neorrealismoneoliberalismo, constructivismo como puente, así como fractura entre racionalismo y reflectivismo. Estos antecedentes supusieron un ejercicio de enfrentamiento y debate que desembocaron en el actual diálogo y, para algunos autores síntesis de ambas corrientes, a cuya evolución se refiere la tabla 2.

${ }^{17}$ Las categorías de centro y periferia fueron desarrolladas en el seno de la CEPAL (Comisión Económica para América Latina) con la influencia de Raúl Prebisch. Básicamente, el centro hacía referencia a los países desarrollados y la periferia a los subdesarrollados. "Centro y periferia se diferencian porque tienen estructuras productivas diferentes: el primero se caracteriza por una estructura diversificada y homogénea; mientras que la segunda, por el contrario, posee una estructura simple y heterogénea. En el centro se genera el progreso técnico y se aplica, con lo que se beneficia de los incrementos de productividad que supone, mientras que la periferia se encuentra supeditada a los avances que se producen en el primero y se beneficia de los mismos no cuando lo quiere y necesita sino cuando se lo permiten" (Alfonso Dubois, 2000). 
Tabla 2: Evolución en los postulados del Neoliberalismo y el Neorrealismo

\begin{tabular}{|l|l|l|l|l|}
\hline & Realismo & Neorrealismo & Liberalismo & Neoliberalismo \\
\hline $\begin{array}{l}\text { Actores } \\
\text { internacionales } \\
\text { y objeto } \\
\text { de análisis }\end{array}$ & $\begin{array}{l}\text { Estado } \\
\text { nación }\end{array}$ & $\begin{array}{l}\text { Acepta otros } \\
\text { actores menos } \\
\text { importantes } \\
\text { Estructura } \\
\text { del sistema } \\
\text { internacional }\end{array}$ & $\begin{array}{l}\text { Pluralidad de } \\
\text { actores }\end{array}$ & Instituciones \\
\hline $\begin{array}{l}\text { Problemática } \\
\text { de estudio }\end{array}$ & $\begin{array}{l}\text { Seguridad } \\
\text { nacional }\end{array}$ & $\begin{array}{l}\text { Lucha por la } \\
\text { posición de poder } \\
\text { en el sistema }\end{array}$ & $\begin{array}{l}\text { Seguridad } \\
\text { colectiva }\end{array}$ & $\begin{array}{l}\text { interestatal } \\
\text { en temas de } \\
\text { la agenda } \\
\text { internacional }\end{array}$ \\
\hline $\begin{array}{l}\text { Motivación } \\
\text { de los actores }\end{array}$ & $\begin{array}{l}\text { Interés } \\
\text { nacional } \\
\text { Poder } \\
\text { Prestigio }\end{array}$ & $\begin{array}{l}\text { Ganancias } \\
\text { relativas }\end{array}$ & $\begin{array}{l}\text { Paz } \\
\text { Prosperidad y } \\
\text { comercio }\end{array}$ & $\begin{array}{l}\text { Ganancias } \\
\text { absolutas }\end{array}$ \\
\hline $\begin{array}{l}\text { Mecanismos } \\
\text { de poder }\end{array}$ & $\begin{array}{l}\text { Equilibrio } \\
\text { de poder } \\
\text { entre } \\
\text { Estados }\end{array}$ & $\begin{array}{l}\text { Distribución } \\
\text { del poder en } \\
\text { la estructura } \\
\text { del sistema } \\
\text { internacional }\end{array}$ & $\begin{array}{l}\text { Organizaciones } \\
\text { y derecho } \\
\text { internacional }\end{array}$ & $\begin{array}{l}\text { Instituciones } \\
\text { regímenes } \\
\text { internacionales }\end{array}$ \\
\hline
\end{tabular}

Fuente: Barbé (2007: 76).

El diálogo entre el neorrealismo y el neoliberalismo fue posible por el acercamiento de posturas entre ambas perspectivas y por la renuncia de importantes autores transnacionalistas a formalizar un paradigma alternativo ${ }^{18}$ al realismo, sobre todo por parte de Joseph Nye y Robert Keohane (Salomón, 2002). Con la nueva formulación del realismo, éste ya no centra tanto su estudio en el Estado, sino en la en las características estructurales del sistema internacional. Además, en esta reformulación del realismo, el nuevo realismo hace uso de las teorías económicas liberales neoclásicas y, como apunta la profesora Salomón (2002). El nuevo transnacionalismo deviene en un denominado neoliberalismo institucional, que cierra la preparación del terreno para el diálogo y la posterior síntesis entre neorrealismo y neoliberalismo. El aspecto institucional del

18 Dicho paradigma alternativo se denominó de la "política mundial". 
neoliberalismo se basa en que los Estados son los principales actores internacionales, aunque no los únicos. Además asumen que los Estados actúan racionalmente y que éstos persiguen alcanzar poder e influencia, aunque no siempre en los mismos términos (Salomón, 2002). Además, la importancia de la cooperación como motor de las relaciones internacionales se torna fundamental para relacionar y compatibilizar las premisas realistas con las liberales, diferenciando cooperación de "armonía de intereses" propugnado por el liberalismo clásico.

De esta manera, la síntesis neo-neo habría quedado como una interpretación de las relaciones internacionales claramente contrapuesta a la visión de la tesis reflectivista resultado de la evolución estructuralista.

\section{Conclusiones}

Como se ha visto en este artículo el ejercicio del poder influye en la concepción de las diversas teorías de las relaciones internacionales, ya que dichas relaciones implican algún tipo de ejercicio del poder. Éste puede ser llevado a cabo mediante el contrato o la opresión y en la dimensión internacional hay que tener en cuenta la manifestación del poder, cuyo paradigma dominante ha sido el denominado realismo.

Tal y como expone el texto, el realismo implica la competencia entre Estados y teniendo en cuenta las concepciones de Foucault (2003), la cristalización más radical y extrema de dicho realismo no sería sino una situación de guerra de razas, identificando éstas como grupos dominantes. A pesar de ello, para los que consideran que se podría superar el escenario de guerra perpetúa, otros dos paradigmas han enfrentado la unívoca visión de las relaciones internacionales que ofrecía el realismo. No obstante, el paradigma transnacionalista, fundamentado en las concepciones kantianas y en la posibilidad de establecer "una paz perpetua", ha evolucionado hacia posiciones cercanas al realismo, durante los años 80 y 90, experimentando una fusión con éste último. Esto implica que la alternativa a las teorías dominantes sobre las relaciones internacionales reside en el estructuralismo rebautizado como reflectivismo. De esta manera se ha consumado una polarización de las teorías de las relaciones internacionales donde, por un lado se encuentran las tesis neo-neo o un liberalismo con su dosis de realismo y, por otro lado, hallamos una perspectiva crítica o reflectivista donde las tesis estructuralistas de base marxista permanecen vivas y se contraponen al análisis liberal en lo político y lo económico.

\section{Bibliografía}

Arenal, C. del (2007): Introducción a las relaciones internacionales, Madrid, Editorial Tecnos, $4^{\mathrm{a}}$ edición.

Arendt, H. (1951): The Origins of Totalitarism, Nueva York, Harcourt, Brace and Company.

Barbé, E. (2007): Relaciones Internacionales, Madrid, Editorial Tecnos, $3^{\mathrm{a}}$ edición.

Clausewitz, C. von (2009): On War: The Complete edition. Rockville, Wildside Press LLC. 
Coulomb, F. (2004): Economic Theories of Peace and War, Nueva York, Editorial Routledge.

Dubois, A. (2000): “Teoría de la dependencia”, en Pérez de Armiño, K. (ed.), Diccionario de Acción Humanitaria y Cooperación al Desarrollo, Barcelona, Hegoa y Editorial Icaria.

Foucault, M. (1988): "El sujeto y el poder", Revista Mexicana de Sociología, 50 (3), Universidad Autónoma de México. México DF.

Foucault, M. (2003): Hay que Defender la Sociedad: Curso del College de France 1975-1976, Madrid, AKAL.

Foucault, M. (2006): Seguridad, Territorio, Población. Curso del College de France 1977-1978, Buenos Aires, Fondo de Cultura Económica.

García Picazo, P. (2006): Teoría breve de relaciones internacionales, Madrid, Editorial Tecnos, $2^{\mathrm{a}}$ edición.

Hernández Sandoica, E. (1992): Los fascismos europeos, Colección La Historia en sus Textos, Madrid, Editorial Istmo.

Hobbes, T. (1980): Leviatán: o la materia, forma y poder de una república eclesiástica y civil, México, Colección Política y Derecho, Fondo de Cultura Económica.

Montt, W. (1997): The economic basis of peace: linkages between economic growth and International conflict, Westport, Greenwood Publishing Group Inc.

Nietzsche, F. (1939): Der Wille zur Macht: Versuch einer Umwertung aller Werte, Leipzig, Alfred Kröner Verlag.

Reich, W. (1989): Materialismo dialéctico y psicoanálisis, México, Siglo XXI editores.

Salomón, M. (2002): "La teoría de las Relaciones Internacionales en los albores del siglo XXI: diálogo, disidencia, aproximaciones", Revista CIDOB d'Afers Internacionals, Barcelona.

Sternhell, Z., M. Sznajder y M. Ashéri (1994): El nacimiento de la ideología fascista, Madrid, Siglo XXI de España Editores.

Weber, M. (2008): Economía y sociedad: esbozo de sociología comprensiva, México, Editorial Fondo de Cultura Económica. 